\title{
Proteome analysis of bronchoalveolar lavage in pulmonary langerhans cell histiocytosis
}

\author{
Claudia Landi ${ }^{2}$, Elena Bargagli ${ }^{*}$, Barbara Magi ${ }^{2}$, Antje Prasse ${ }^{3}$, Joachim Muller-Quernheim ${ }^{3}$, Luca Bini ${ }^{2}$ and \\ Paola Rottoli ${ }^{1}$
}

\begin{abstract}
Background: Pulmonary Langerhans-cell histiocytosis $(\mathrm{PLCH})$ is a rare interstitial lung disease characterized by clusters of Langerhans cells, organized in granulomas, in the walls of distal bronchioles. It is a diffuse lung disease related to tobacco smoking but otherwise of unknown etiopathogenesis.
\end{abstract}

Methods: In this study we used a proteomic approach to analyze BAL protein composition of patients with PLCH and of healthy smoker and non-smoker controls to obtain insights into the pathogenetic mechanisms of the disease, to study the effect of cigarette smoking on susceptibility to PLCH and to identify potential new biomarkers.

Results: Two-dimensional electrophoresis and image analysis revealed proteins that were differently expressed (quantitatively and qualitatively) in the three groups of subjects. The proteins were identified by mass spectrometry and have various functions (antioxidant, proinflammatory, antiprotease) and origins (plasma, locally produced, etc.). Many, such as protease inhibitors (human serpin B3) and antioxidant proteins (glutathione peroxidase and thioredoxin) are already linked to PLCH pathogenesis, whereas other proteins have never been associated with the disease. Interestingly, numerous proteolytic fragments of plasma proteins (including kininogen-1 $\mathrm{N}$ fragments and haptoglobin) were also identified and suggest increased proteolytic activity in this inflammatory lung disease. Differences in protein expression were found between the three groups and confirmed by Principal Component Analysis (PCA).

Conclusion: Analysis of BAL proteomes of PLCH patients and of smoker and non-smoker controls also proved to be useful for researching the pathogenetic mechanisms and for identifying biomarkers of this rare diffuse lung disease.

\section{Introduction}

Pulmonary Langerhans cell histiocytosis (PLCH) is a rare granulomatous disorder characterized by uncontrolled proliferation and infiltration of CD1+ Langerhans cells (LCs) in the lung. It has been associated with smoking and prevalently affects young adults $[1,2]$. The pathogenesis of PLCH is unclear. The bronchiolar distribution of lesions suggests that an inhaled antigen, such as cigarette smoke, may be involved, since $90 \%$ of cases are smokers [3]. The correlation between PLCH and smoking is corroborated by recent studies demonstrating that acute tobacco smoke inhalation determines

\footnotetext{
* Correspondence: bargagli2@gmail.com

'Respiratory Diseases Section, Department of Clinical Medicine and

Immunological Sciences, University of Siena, Siena (Italy

Full list of author information is available at the end of the article
}

immediate and selective recruitment of LCs into human airways, inducing a very early reaction of the adaptive immune system [4-6]. Moreover, cigarette smoke promotes survival signals and prolongs survival of dendritic cells [7]. Smoke-induced alterations at lung level can therefore induce changes in lung condition determining a typical protein profile at bronchoalveolar and plasma level.

Proteomics is a powerful approach that enables lung diseases to be studied through the characterization and identification of protein marker profiles that can highlight specific pathological states. A proteomic approach to the study of BAL is extremely useful for insights into pathogenesis and identification of biomarkers [8]. There is no literature on BAL proteomic findings in PLCH. We therefore studied BAL protein composition in 
PLCH patients, healthy non-smoker controls and healthy smoker controls by a proteomic approach using two-dimensional electrophoresis (2-DE) and mass spectrometry (MS) in order to obtain insights into the pathogenesis of $\mathrm{PLCH}$, to evaluate the effect of smoking on disease progression and to discover new prognostic biomarkers.

\section{Materials and methods Population}

The study population consisted of five PLCH patients of Caucasian race ( 3 female, mean age $33.15 \pm 36.13$ years), five healthy non-smokers ( 3 female, mean age $59.13 \pm 24.2$ ) and five healthy smokers (2 female, mean age $43.17 \pm 29.62$ ) monitored at Siena Regional Referral Centre for Interstitial Lung Diseases for a period of at least four years. All patients were currently smokers with the exception of a single patient who was an exsmoker. We analyzed exposure of our patients to environmental pollution retrospectively and interestingly, none of the patients lived in big cities: all came from the country or small towns with no significant exposure to pollutants. No professional risk was found as $3 / 5$ were office workers, another a teacher and the fifth a cook. Diagnosis of PLCH was conducted according to international criteria [9-11]; three patients had a diagnosis based on histological examination of transbronchial biopsies showing tissue positivity for anti-CD1a and S100 protein staining; the other two had a diagnosis based on clinical-radiological findings and BAL features (including CD1a positivity). All patients underwent pulmonary function tests (PFT) and gas exchange evaluation according to ERS guidelines [12]. All patients gave their written informed consent to enrolment in the study.

\section{Bronchoalveolar lavage}

Bronchoscopy with BAL was performed in all patients for diagnostic reasons as previously reported [13-15]. Lymphocyte phenotype was analyzed by flow cytometry (Facs-Calibur, Becton Dickinson) using anti -CD3, -CD4, -CD8 and -CD1a monoclonal antibodies.

\section{Two-Dimensional Gel Electrophoresis (2DE)}

BAL samples were dialyzed against water, lyophilized and dissolved in lysis buffer (8 M urea, 4\% CHAPS, 40 $\mathrm{mM}$ Tris base, $65 \mathrm{mM}$ dithioerythritol and trace amounts of bromophenol blue). Protein concentration was determined according the Bradford method [16]. 2DE was carried out using the Immobiline polyacrylamide system, as previously described [17] on a preformed immobilized nonlinear $\mathrm{pH}$ gradient, from $\mathrm{pH} 3$ to $10,18 \mathrm{~cm}$ length, from GE Healthcare (Uppsala, Sweden). Sample load was $60 \mu \mathrm{g}$ per strip in analytical runs, and $1 \mathrm{mg}$ per strip in preparative gels. Analytical runs were carried out using the Ettan ${ }^{\mathrm{TM}}$ IPGphor ${ }^{\mathrm{TM}}$ system (Amersham Biosciences) at $16^{\circ} \mathrm{C}$ under the following electrical conditions: $0 \mathrm{~V}$ for $1 \mathrm{~h}, 30 \mathrm{~V}$ for $8 \mathrm{~h}$, $200 \mathrm{~V}$ for $1 \mathrm{~h}$, from 300 to $3500 \mathrm{~V}$ in $30 \mathrm{~min}, 3500 \mathrm{~V}$ for $3 \mathrm{~h}$, from 3500 to $8000 \mathrm{~V}$ in $30 \mathrm{~min}, 8000 \mathrm{~V}$ up to a total of $80,000 \mathrm{Vh}$. Preparative strips were rehydrated with $350 \mu \mathrm{L}$ UREA $8 \mathrm{M}, 4 \% \mathrm{w} / \mathrm{v}$ CHAPS, $1 \% \mathrm{w} / \mathrm{v}$ DTE and $2 \% \mathrm{v} / \mathrm{v}$ carrier ampholyte at room temperature for 12 h. Sample load was obtained by cup loading, with the cup applied at the cathodic and anodic ends of the strip. MS-preparative runs were obtained using the Multiphor ${ }^{\mathrm{TM}}$ II electrophoresis system and the following voltage steps at $16^{\circ} \mathrm{C}$ : $200 \mathrm{~V}$ for $6 \mathrm{~h}, 600 \mathrm{~V}$ for $1 \mathrm{~h}$, $1200 \mathrm{~V}$ for $1 \mathrm{~h}, 3500 \mathrm{~V}$ for $3 \mathrm{~h}, 5000 \mathrm{~V}$ for $14 \mathrm{~h}$. After the first dimension run, the IPG gels were equilibrated in $6 \mathrm{M}$ urea, $2 \% \mathrm{w} / \mathrm{v}$ SDS, $2 \% \mathrm{w} / \mathrm{v}$ DTE, $30 \% \mathrm{v} / \mathrm{v}$ glycerol and $0.05 \mathrm{M}$ Tris- $\mathrm{HCl} \mathrm{pH} 6.8$ for $12 \mathrm{~min}$; and for a further $5 \mathrm{~min}$ in $6 \mathrm{M}$ urea, $2 \% \mathrm{w} / \mathrm{v}$ SDS, $2.5 \% \mathrm{w} / \mathrm{v}$ iodoacetamide, $30 \% \mathrm{v} / \mathrm{v}$ glycerol, $0.05 \mathrm{M}$ Tris- $\mathrm{HCl} \mathrm{pH}$ 6.8 and a trace of bromophenol blue. After the two equilibration steps, the second dimensional separation was performed on 9-16\% SDS polyacrylamide linear gradient gels $(18 \times 20 \mathrm{~cm} \times 1.5 \mathrm{~mm})$, and carried out at $40 \mathrm{~mA} /$ gel constant current, at $9^{\circ} \mathrm{C}$ until the dye front reached the bottom of the gel [18]. Analytical gels were stained with ammoniacal silver nitrate $[19,20]$. MS-preparative gels were stained with SYPRO Ruby (Bio-rad headquarters, Hercules, California) according to the manufacturer's instructions. Bindsilane $(\gamma$ methacryloxypropyltrimethoxysilane) (LKBProdukter AB, Brommo, Sweden) was used to attach polyacrylamide gels covalently to a glass surface for those undergoing SYPRO Ruby staining [21]. Ammoniacal silver nitrate stained gels were then digitized by a Molecular Dynamics $300 \mathrm{~S}$ laser densitometer $(4000 \times 5000$ pixels, 12 bits/pixel; Sunnyvale, CA, USA). Preparative gel images stained with SYPRO Ruby were digitized with a Typhoon 9400 laser densitometer (GE Healthcare). Computer-aided 2D image analysis was carried out with the Image Master Platinum 7.0 computer system (GE Healthcare). Spot detection was achieved after defining and saving a set of detection parameters, enabling filtering and smoothing of the original gel scans to clarify spots, and removal of vertical and horizontal streaks and speckles. The analysis process was performed by matching all gels of each group with a reference gel for the same condition with the best resolution and greatest number of spots, chosen by the user and named "master" by the software. The three master reference gels were then matched with each other. By this procedure, the Image Master Platinum algorithm matched the other gels to find qualitative and quantitative differences. 


\section{Statistical analysis}

Statistical analysis of the samples was performed using Statistical software packages SPSS 13.0 for Windows and Graphpad Prism 5 for Windows. Data was expressed as mean \pm standard deviation $(\mathrm{M} \pm \mathrm{SD})$. For the proteomic approach, statistical analysis of proteins expressed differently in the three groups was carried out using Student's T-test, one-way ANOVA and Tukey's test. Only unmatched spots or spots with significantly different $\% \mathrm{~V}$ ( $\mathrm{p}<0.05$ by ANOVA) were considered "differently expressed" in the three groups.

\section{Mass Spectrometry}

Protein identification was carried out by PMF on an Ettan MALDI-TOF Pro (GE Healthcare), as previously described [22,23]. Electrophoretic spots from SYPRO Ruby stained gels were mechanically excised by an Ettan Spot Picker (GE Healthcare), destained in $2.5 \mathrm{mM}$ ammonium bicarbonate and 50\% acetonitrile, and dehydrated in acetonitrile. They were then rehydrated in trypsin solution and digested overnight at $37^{\circ} \mathrm{C} .0 .75 \mu \mathrm{L}$ of each protein digest was spotted onto the MALDI target and allowed to dry. Then $0.75 \mu \mathrm{L}$ of matrix solution (saturated solution of CHCA in 50\% v/v ACN and $0.5 \%$ $\mathrm{v} / \mathrm{v}$ TFA) was applied to the dried sample, and dried again. After acquiring the mass of the peptide, a mass fingerprinting search was carried out in Swiss-Prot/ TrEMBL and NCBInr databases using MASCOT (Matrix Science Ltd., London, UK, http://www. matrixscience.com) software available on-line. Taxonomy was limited to Mammalia, mass tolerance was 100 ppm, and the number of missed cleavage sites accepted was set at one. Alkylation of cysteine by carbamidomethylation was assumed and oxidation of methionine was considered as a possible modification. Sequence coverage, number of matched peptides and probability score are shown in the tables.

\section{Multivariate analysis}

Principal Components Analysis (PCA) was performed for the three groups to reduce proteomic data complexity and to identify meaningful groups and associations in the dataset. PCA transforms a number of correlated variables (e.g. individual protein spot abundance levels in each experimental sample) into a smaller number of uncorrelated variables, called principal components. In this study PCA was used to cluster the experimental groups on the basis of protein spot expression in BAL (spot maps). Percentage volumes of spots differently expressed in the three analysis groups (PLCH versus non-smoker controls, PLCH versus smoker controls and non-smoker versus smoker controls) were included in the PCA analysis, which was performed using STATISTICA 7.0 software (Statsoft, Inc.). In the resulting graph, the spot maps were plotted in two-dimensional space, showing the principal components PC1 and PC2 that divided the samples analyzed orthogonally according to the two principal sources of variation in the data set.

\section{Results}

\section{Population}

Table 1 reports the clinical features, LFT and bronchoalveolar lavage results of the group of $\mathrm{PLCH}$ patients. As expected, BAL cell profile showed eosinophilia greater than 6\%, mild neutrophilia and 8.1\% [ \pm 5.3] CD1a-positive cells. Low DLCO was evident in all patients at the time of bronchoscopy and lung function tests revealed obstructive pattern in 2 patients, restrictive deficit in 1 patient and a normal functional pattern in the other 2 cases.

\section{Proteome analysis}

Figure 1 shows the master gels of the three groups (PLCH patients and smoker/non-smoker controls), chosen as reference gels because of their high resolution and large number of protein spots. An average of 1100 spots was detected in each gel across groups. When our master gels were matched by Image Master Platinum 7.0, qualitative and quantitative protein differences were observed. MALDI-ToF/MS identified these proteins, including two found for the first time in BAL samples: serpin B3 (SPB3) and plastin-2 (PLSL), which were upregulated in smokers versus non-smokers and downregulated in $\mathrm{PLCH}$ patients versus smokers. Among spots expressed differently between groups, there were modulators of immune responses (such as polymeric immunoglobulin receptor (PIGR), immunoglobulin light chain, Ig alpha-1 chain $C$ region, PLSL, Ig gamma-1 chain $\mathrm{C}$ region, IgG $\mathrm{K}$ chain), proteins implicated in antioxidant defence (thioredoxin (THIO), albumin (ALBU), ceruloplasmin (CERU), glutathione peroxidase

Table 1 Clinical characteristics, BAL and LFT features of our PLCH population.

\begin{tabular}{ll}
\hline NUMBER OF PATIENTS & 5 \\
\hline AGE & $33,15 \pm 36,13$ \\
\hline GENDER & 2 MALE \\
\hline BAL MACROPHAGES (\%) & $77,2 \pm 15,6$ \\
\hline BAL LYMPHOCYTES (\%) & $9,9 \pm 19,3$ \\
\hline BAL NEUTROPHILS (\%) & $4,7 \pm 2,1$ \\
\hline BAL EOSINOPHILS (\%) & $6,88 \pm 3,4$ \\
\hline CD1+ & $8,1 \pm 5,3$ \\
\hline OBSTRUCTIVE & 2 \\
\hline RESTRICTIVE & 1 \\
\hline DECREASED & 5 \\
DLCO & \\
\hline
\end{tabular}




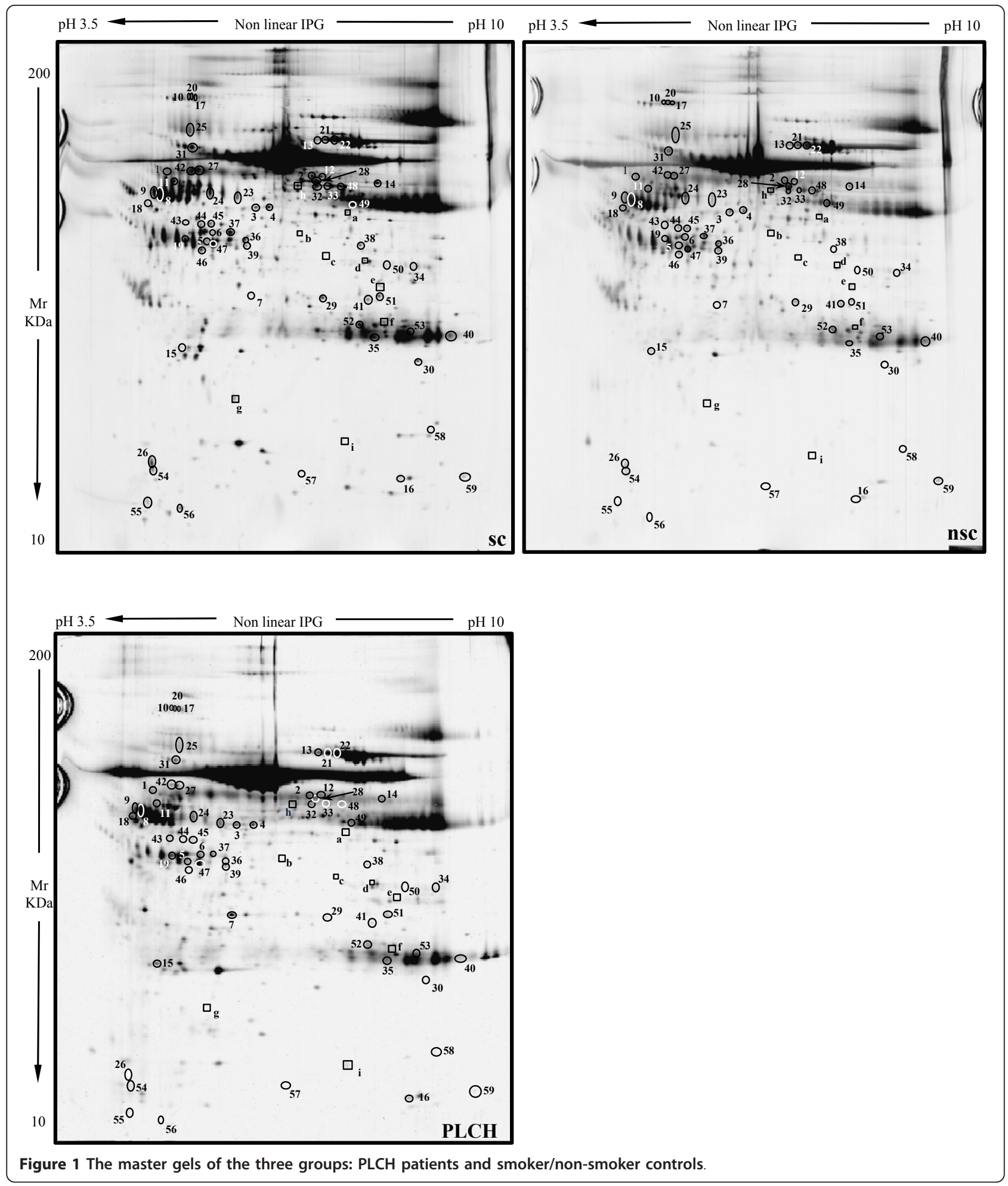

3 (GPX3)), cell-cycle regulators (creatinine kinase BType, ADP ribosylation factor-like protein 3 and annexin A3 (ANXA3)), proteins involved in ion transport (such as serotransferrin (TRFE) and hemoglobin subunit beta) and several inflammatory proteins (including pigment epithelium derived factor (PEDF) and apolipoprotein A1 (APOA1)). Alpha-1-antitrypsin (A1AT) isoforms and SPB3 were spots with anti-protease 
function. Other proteins like purine nucleoside phosphorylase, pyruvate kinase isozymes, fibrinogen gamma chain, alpha 1B glycoprotein and actin cytoplasmic 1 were identified. BAL proteome analysis of $\mathrm{PLCH}$ patients also revealed several proteolytic fragments of plasma proteins, such as albumin (ALBU), haptoglobin (HPT) and kininogen-1 (KNG1). Five isoforms of alpha 1 anti-trypsin (A1AT) were differentially expressed in BAL of the three groups.

Considering only spots constantly present in all gels of all groups, significant qualitative variations in sensitivity to silver staining were observed for the nine spots (Table 2). Some of these proteins were found in healthy controls but not in patients and others were found in PLCH and smoker-control samples but not in those of non-smoker controls. Fifty nine spots showed at least \pm 2 times variations in percentage of relative volume (\%V) (\%V = Vsingle spot/Vtotal spot). These spots were significantly up- or down-regulated in BAL samples of PLCH patients with respect to BAL of smoker and nonsmoker controls $(\mathrm{p}<0.05)$. Tables 3,4 and 5 list the proteins identified from these spots with their accession numbers, theoretical and experimental molecular weights, pIs, Mascot search results, mean and standard deviations, statistical $p$ values and number of folds of protein expression in the three groups.

Twenty-eight spots were quantitatively more abundant in PLCH than in non-smoker and/or smoker control samples. The proteins of $24 / 28$ spots were identified and are listed in Table 3. KNG1 fragment N-terminal ( $\mathrm{p}$ $<0.00001)$ and an isoform of A1AT were strongly upregulated in $\mathrm{PLCH}$ patients with respect to controls (Table 3). Figure 2 shows the expression of KNG1 Nterminal fragment (an inflammatory protein never studied in PLCH) in patients and controls. The percentage volume of two spots identified as PEDF (a protease inhibitor) were particularly elevated in patients than controls $(\mathrm{p}<0.001)$ (Figure 3). Another protein involved in cell proliferation, motility, invasiveness and signaling pathways, up-regulated in PLCH with respect to controls $(\mathrm{p}<0.01)$ and potentially involved in pathogenesis, is ANXA3 (Figure 4).

Thirteen spots were down-regulated in PLCH compared to non-smoker and/or smoker controls (Table 4). The protein spots PIGR, THIO and PLSL were downregulated in PLCH compared to controls and are of particular interest because of their specific functions and potential implication in the disease. Figures 5 and 6 show the trend of expression of PIGR, THIO percentage volumes in patients and controls.

Seventeen spots were also significantly differently expressed between healthy smoker and non-smoker controls, as well as between controls and PLCH patients; $10 / 17$ were identified (table 5). Table 5 is divided in two parts: the first includes protein spots significantly downregulated in non-smoker compared to smoker controls; the second includes spots up-regulated in non-smoker compared to smoker controls. Among the spots upregulated in smokers, SPB3 is a protein with anti-protease function identified de novo in BAL; there is no literature on SPB3 and smoke-induced lung damage.

\section{Multivariate analysis}

Multivariate statistical analysis by PCA was used to examine global trends in protein expression in BAL of PLCH patients and non-smoker and smoker controls. These samples were grouped according to the variance of their protein expression $(\% \mathrm{~V})$ and their spatial distribution is shown in Figure 7. The first principal component (PC1) explained $49.94 \%$ of the variance and the second (PC2) explained a further $20.06 \%$. PCA showed that PLCH and control samples clustered in distinct groups along the PC2 axis. In the control cluster, there were two other distinct groups very close to each other: those of non-smoker and smoker controls.

\section{Discussion}

BAL protein expression analyzed by 2DE in a population of PLCH patients was compared with that of control samples. Bioinformatics analysis identified a wide range of spots expressed differently in BAL of PLCH patients with respect to BAL of healthy controls. The effect of cigarette smoking on the expression of some proteins was also evaluated, comparing BAL protein patterns of smoker and non-smoker controls.

\section{Population}

The clinical, immunological and functional features of our PLCH patients indicated prevalently obstructive lung function deficit, increased BAL CD1a+ cells together with neutrophilia and eosinophilia, in line with the literature $[1,2]$.

\section{DE}

Proteomic analysis of BAL revealed 59 spots expressed with quantitative differences and 9 spots expressed with qualitative differences in BAL of PLCH patients with respect to controls. The proteins identified from these spots are involved in specific biological mechanisms (inflammation, immunity, oxidative stress, protease-antiprotease balance, cell proliferation, fibrosis) potentially implicated in the pathogenesis of PLCH. Some of these proteins need to be studied in detail, as they could be useful diagnostic or prognostic biomarkers.

Two proteins never described in BAL were identified de novo: serpin B3 and plastin 2. The first, up-regulated in smokers and higher (with borderline significance $\mathrm{p}=$ 0.05) in PLCH than controls, is a member of the family 
Table 2 Proteins identified in BAL qualitatively differently expressed in PLCH patients than controls.

\begin{tabular}{|c|c|c|c|c|c|c|c|c|c|c|c|c|}
\hline \multirow{2}{*}{$\begin{array}{l}\text { Spot } \\
\text { letter }\end{array}$} & \multirow[t]{2}{*}{ Protein name } & \multirow[t]{2}{*}{$A C$} & \multirow{2}{*}{$\begin{array}{c}\text { Theoretical pl/ } \\
\text { Mr (KDa) }\end{array}$} & \multirow{2}{*}{$\begin{array}{c}\text { Experimental pl/ } \\
\mathrm{Mr}(\mathrm{KDa})\end{array}$} & \multicolumn{3}{|c|}{ Mascot search result } & \multicolumn{3}{|c|}{ Mean $\% \mathrm{~V} \pm \mathrm{SD} \times 10^{-4}$} & \multirow{2}{*}{$\begin{array}{c}\text { 1-way ANOVA } p \\
\text { value }\end{array}$} & \multirow[t]{2}{*}{ Localization } \\
\hline & & & & & $\begin{array}{l}\text { No. of matched } \\
\text { peptide }\end{array}$ & $\begin{array}{l}\text { Sequence } \\
\text { coverage }\end{array}$ & Score & nsc & sc & $\mathrm{PLCH}$ & & \\
\hline \multirow[t]{2}{*}{ a } & $\begin{array}{l}\text { Serum albumin, } \\
\text { fragment c-term }\end{array}$ & P02768 & 5.92 & 6.3 & 5 & 11 & 64 & $67 \pm 68^{*}$ & $175 \pm 56^{* *}$ & $0^{*}$ & 0,0005 & Plasma \\
\hline & & & 71317 & 47485 & & & & & & & & \\
\hline \multirow[t]{2}{*}{ B } & $\begin{array}{l}\text { Serum albumin, } \\
\text { fragment c-term }\end{array}$ & P02768 & 5.92 & 5.9 & 10 & 20 & 128 & $28 \pm 39^{*}$ & $125 \pm 69 * *$ & $0^{*}$ & 0,002 & Plasma \\
\hline & & & 71317 & 41761 & & & & & & & & \\
\hline \multirow[t]{2}{*}{ D } & Alcohol dehydrogenase & P14550 & 6.32 & 6.44 & 15 & 52 & 223 & $90 \pm 101 *$ & $396 \pm 159^{* *}$ & $0^{*}$ & 0,0002 & Cytoplasm \\
\hline & & & 36892 & 37399 & & & & & & & & \\
\hline \multirow[t]{2}{*}{ e } & Annexin A1 & P04083 & 6.57 & 6.57 & 12 & 42 & 179 & $22 \pm 35^{*}$ & $326 \pm 265^{* *}$ & $0^{*}$ & 0,009 & $\begin{array}{l}\text { Cytoplasm- } \\
\text { Nucleus }\end{array}$ \\
\hline & & & 38918 & 33339 & & & & & & & & \\
\hline \multirow[t]{2}{*}{ g } & $\begin{array}{c}\text { Glutathione peroxidase } \\
3\end{array}$ & P22352 & 8.26 & 5.48 & 9 & 34 & 121 & $108 \pm 40^{*}$ & $386 \pm 229 * *$ & $0^{*}$ & 0,001 & Plasma \\
\hline & & & 25765 & 17509 & & & & & & & & \\
\hline \multirow[t]{2}{*}{$\mathrm{h}$} & Beta-2-glycoprotein 1 & P02749 & 8.34 & 5.89 & 6 & 28 & 91 & $0^{*}$ & $997 \pm 277 * *$ & $\begin{array}{c}319 \\
\pm 253^{*}\end{array}$ & $3,27 \mathrm{E}-05$ & Plasma \\
\hline & & & 39584 & 56152 & & & & & & & & \\
\hline \multirow[t]{2}{*}{ i } & $\begin{array}{l}\text { Serum albumin, } \\
\text { fragment c-term }\end{array}$ & P02768 & 5.92 & 6.25 & 8 & 11 & 78 & $0^{\S}$ & $61 \pm 97^{*}$ & $\begin{array}{c}381 \\
\pm 254^{* \S}\end{array}$ & 0,005 & Plasma \\
\hline & & & 71317 & 14042 & & & & & & & & \\
\hline
\end{tabular}


Table 3 List of identified proteins with their accession numbers, theoretical and experimental molecular weights, p/s,

\begin{tabular}{|c|c|c|c|c|c|c|c|c|c|c|c|c|c|c|c|}
\hline \multirow{2}{*}{$\begin{array}{l}\text { No. of } \\
\text { spot }\end{array}$} & \multirow[t]{2}{*}{ Protein name } & \multirow[t]{2}{*}{$\mathrm{AC}$} & \multirow{2}{*}{$\begin{array}{l}\text { Theoretical } \\
\mathrm{pl} / \mathrm{Mr} \\
\text { (KDa) }\end{array}$} & \multirow{2}{*}{$\begin{array}{l}\text { Experimental } \\
\text { pl/Mr (KDa) }\end{array}$} & \multicolumn{3}{|c|}{ Mascot search result } & \multicolumn{3}{|c|}{ Mean $\% \mathrm{~V} \pm \mathrm{SD} \times 10-4$} & \multirow{2}{*}{$\begin{array}{l}\text { 1-way } \\
\text { ANOVA p } \\
\text { value }\end{array}$} & \multicolumn{3}{|c|}{ Folds in } & \multirow[t]{2}{*}{ Localization } \\
\hline & & & & & $\begin{array}{l}\text { No. of } \\
\text { matched } \\
\text { peptide }\end{array}$ & $\begin{array}{c}\text { Sequence } \\
\text { coverage } \\
(\%)\end{array}$ & Score & nsc & sc & $\mathrm{PLCH}$ & & $\begin{array}{l}\text { Nsc- } \\
\text { sc }\end{array}$ & $\begin{array}{l}\text { Nsc- } \\
\text { PLCH }\end{array}$ & $\begin{array}{l}\text { Sc- } \\
\text { PLCH }\end{array}$ & \\
\hline \multicolumn{16}{|c|}{$\begin{array}{c}\mathrm{PLCH}> \\
\mathrm{nsc} \text { and/or } \\
\text { sc }\end{array}$} \\
\hline \multirow[t]{2}{*}{1} & $\begin{array}{l}\text { Kininogen-1, } \\
\text { fragment } N \text { - } \\
\text { term }\end{array}$ & P01042 & 6.34 & 4.95 & 11 & 18 & 118 & $543 \pm 105^{\S}$ & $225 \pm 214^{*}$ & $5393 \pm 1864^{\# \S}$ & 8.97E-06 & 2.41 & $9.93^{5}$ & $23.96^{*}$ & $\begin{array}{l}\text { Secreted- } \\
\text { extracellular } \\
\text { space }\end{array}$ \\
\hline & & & 72996 & 61092 & & & & & & & & & & & \\
\hline \multirow[t]{2}{*}{2} & $\begin{array}{c}\text { Ig alpha-1 } \\
\text { chain C region }\end{array}$ & P01876 & 6.08 & 5.98 & 8 & 25 & 116 & $879 \pm 788^{\S}$ & $206 \pm 207^{*}$ & $3179 \pm 1685^{* 5}$ & 0,002 & 4.26 & $3.61^{\S}$ & $15.43^{*}$ & Secreted \\
\hline & & & 38486 & 60221 & & & & & & & & & & & \\
\hline \multirow[t]{2}{*}{3} & $\begin{array}{l}\text { Pigment } \\
\text { epithelium }\end{array}$ & P36955 & 5.97 & 5.61 & 8 & 24 & 111 & $405 \pm 176^{\S}$ & $281 \pm 87^{*}$ & $1230 \pm 693^{\# \S}$ & 0,007 & 1.44 & $3.03^{\S}$ & $4.37^{*}$ & Secreted \\
\hline & & & 46484 & 49075 & & & & & & & & & & & \\
\hline \multirow[t]{2}{*}{4} & $\begin{array}{l}\text { Pigment } \\
\text { epithelium }\end{array}$ & P36955 & 5.97 & 5.69 & 8 & 21 & 114 & $326 \pm 211^{\S}$ & $307 \pm 182^{*}$ & $767 \pm 260^{\neq \S}$ & 0,009 & 1.06 & $2.35^{\S}$ & $2.49^{*}$ & Secreted \\
\hline & & & 46484 & 49222 & & & & & & & & & & & \\
\hline \multirow[t]{2}{*}{5} & $\begin{array}{l}\text { Haptoglobin, } \\
\text { fragment c- } \\
\text { term. }\end{array}$ & P00738 & 6.13 & 5.26 & 12 & 31 & 114 & $446 \pm 69^{\S}$ & $432 \pm 180^{*}$ & $2062 \pm 1186^{¥ 5}$ & 0,003 & 1.03 & $4.62^{\S}$ & $4.77^{*}$ & Plasma \\
\hline & & & 45861 & 40355 & & & & & & & & & & & \\
\hline \multirow[t]{2}{*}{6} & $\begin{array}{c}\text { Creatine kinase } \\
\text { B-type }\end{array}$ & P12277 & 5.34 & 5.31 & 7 & 26 & 108 & $267 \pm 146^{\S}$ & $161 \pm 93^{*}$ & $749 \pm 306^{* \S}$ & 0,001 & 1.65 & $2.80^{\S}$ & $4.65^{*}$ & Cytoplasm \\
\hline & & & 42902 & 41841 & & & & & & & & & & & \\
\hline \multirow[t]{2}{*}{7} & Annexin A3 & P12429 & 5.63 & 5.59 & 8 & 32 & 111 & $158 \pm 159^{\S}$ & $127 \pm 54^{*}$ & $530 \pm 318^{\# \S}$ & 0,017 & 1.24 & $3.35^{\S}$ & $4.17^{*}$ & Cytoplasm \\
\hline & & & 36524 & 31681 & & & & & & & & & & & \\
\hline \multirow[t]{2}{*}{8} & $\begin{array}{l}\text { Alpha-1 anti } \\
\text { tripsin }\end{array}$ & P01009 & 5.37 & 4.84 & 15 & 46 & 212 & $1491 \pm 1178^{\S}$ & $299 \pm 413^{*}$ & $5425 \pm 817^{\# \S}$ & 1,79E-06 & 4.98 & $3.63^{\S}$ & $18.14^{*}$ & Plasma \\
\hline & & & 46878 & 53626 & & & & & & & & & & & \\
\hline \multirow[t]{2}{*}{9} & $\begin{array}{l}\text { Alpha-1 anti } \\
\text { tripsin }\end{array}$ & P01009 & 5.37 & 4.8 & 8 & 27 & 107 & $495 \pm 979^{\S}$ & $28 \pm 64^{*}$ & $2644 \pm 1473^{* \S}$ & 0,003 & 17.6 & $5.34^{\S}$ & $94.42^{*}$ & Plasma \\
\hline & & & 46878 & 54359 & & & & & & & & & & & \\
\hline \multirow[t]{2}{*}{10} & Ceruloplasmin & P00450 & 5.44 & 5.1 & 11 & 13 & 134 & $135 \pm 118^{\S}$ & $154 \pm 149^{*}$ & $496 \pm 121^{¥ 5}$ & 0,001 & 1.14 & $3.67^{\S}$ & $3.22^{*}$ & Plasma \\
\hline & & & 122983 & 131973 & & & & & & & & & & & \\
\hline 11 & $\begin{array}{l}\text { Alpha-1- } \\
\text { antitrypsin }\end{array}$ & P01009 & 5.37 & 4.96 & 13 & 41 & 175 & $288 \pm 221^{\S}$ & $423 \pm 204^{*}$ & $1359 \pm 551^{\# \S}$ & 0,001 & 1.46 & $4.71^{\S}$ & $3.21^{*}$ & Plasma \\
\hline
\end{tabular}


Table 3 List of identified proteins with their accession numbers, theoretical and experimental molecular weights, p/s, (Continued)

\begin{tabular}{|c|c|c|c|c|c|c|c|c|c|c|c|c|c|c|c|}
\hline & & & 46878 & 58032 & & & & & & & & & & & \\
\hline \multirow[t]{2}{*}{12} & Serotransferrin & P02787 & 6.81 & 6.05 & 8 & 11 & 102 & $415 \pm 322^{\S}$ & $162 \pm 219^{*}$ & $2655 \pm 1223^{\# 5}$ & 0,0003 & 2.56 & $6.39^{\S}$ & $16.38^{*}$ & Plasma \\
\hline & & & 79280 & 60048 & & & & & & & & & & & \\
\hline \multirow[t]{2}{*}{13} & Serotransferrin & P02787 & 6.81 & 6 & 11 & 19 & 112 & $623 \pm 170^{\S}$ & $672 \pm 576^{*}$ & $3255 \pm 2316^{75}$ & 0,016 & 1.07 & $5.22^{5}$ & $4.84^{*}$ & Plasma \\
\hline & & & 79280 & 80091 & & & & & & & & & & & \\
\hline \multirow[t]{2}{*}{14} & $\begin{array}{l}\text { Pyruvate kinase } \\
\text { isozymes }\end{array}$ & P14618 & 7.96 & 6.47 & 11 & 28 & 105 & $276 \pm 236^{5}$ & $642 \pm 290^{*}$ & $1391 \pm 596^{\text {₹\$ }}$ & 0,003 & 2.32 & $5.03^{\S}$ & $2.16^{*}$ & $\begin{array}{l}\text { Cytoplasm- } \\
\text { Nucleus }\end{array}$ \\
\hline & & & 58470 & 58174 & & & & & & & & & & & \\
\hline \multirow[t]{2}{*}{15} & $\begin{array}{c}\text { Apolipoprotein } \\
\text { A-I }\end{array}$ & P02647 & 5.56 & 5.03 & 8 & 26 & 99 & $179 \pm 103^{\S}$ & $276 \pm 197^{*}$ & $924 \pm 371^{¥ \S}$ & 0,0009 & 1.54 & $5.16^{\S}$ & $3.34^{*}$ & Plasma \\
\hline & & & 30759 & 23065 & & & & & & & & & & & \\
\hline \multirow[t]{2}{*}{16} & $\begin{array}{l}\text { Hemoglobin } \\
\text { subunit beta }\end{array}$ & P68871 & 6.75 & 6.77 & 11 & 77 & 155 & $109 \pm 131^{\S}$ & $\begin{array}{l}328 \pm \\
123^{*} \\
\end{array}$ & $650 \pm 233^{* 5}$ & 0,001 & 3 & $5.96^{\S}$ & $1.98^{*}$ & Blood \\
\hline & & & 16102 & 11120 & & & & & & & & & & & \\
\hline \multirow[t]{2}{*}{17} & Ceruloplasmin & P00450 & 5.44 & 5.13 & 15 & 18 & 123 & $259 \pm 183^{\S}$ & $180 \pm 179^{*}$ & $564 \pm 99^{* \S}$ & 0,005 & 1.43 & $2.17^{\S}$ & $3.13^{*}$ & Plasma \\
\hline & & & 122983 & 130654 & & & & & & & & & & & \\
\hline \multirow[t]{2}{*}{18} & $\begin{array}{l}\text { Alpha-1- } \\
\text { antitrypsin }\end{array}$ & P01009 & 5.37 & 4.7 & 11 & 32 & 143 & $277 \pm 290$ & $93 \pm 77^{*}$ & $599 \pm 288^{*}$ & 0,018 & 2.97 & 2.16 & $6.44^{*}$ & Plasma \\
\hline & & & 46878 & 50566 & & & & & & & & & & & \\
\hline \multirow[t]{2}{*}{19} & $\begin{array}{c}\text { Actin, } \\
\text { cytoplasmic } 1\end{array}$ & P60709 & 5.29 & 5.07 & 9 & 28 & 107 & $867 \pm 437$ & $320 \pm 272^{*}$ & $1071 \pm 348^{*}$ & 0,016 & 2.7 & 1.23 & $3.34^{*}$ & Cytoskeleton \\
\hline & & & 42052 & 40664 & & & & & & & & & & & \\
\hline \multirow[t]{2}{*}{20} & Ceruloplasmin & P00450 & 5.44 & 5.16 & 10 & 11 & 101 & $306 \pm 223$ & $201 \pm 151^{*}$ & $537 \pm 137^{*}$ & 0,02 & 1.52 & 1.75 & $2.67^{*}$ & Plasma \\
\hline & & & 122983 & 130000 & & & & & & & & & & & \\
\hline \multirow[t]{2}{*}{21} & Serotransferrin & P02787 & 6.81 & 6.07 & 16 & 22 & 166 & $1085 \pm 228^{\S}$ & $\begin{array}{r}1831 \\
\pm 559 \\
\end{array}$ & $4471 \pm 2939^{\S}$ & 0,022 & 1.68 & $4.12^{\S}$ & 2.44 & Plasma \\
\hline & & & 79280 & 80.091 & & & & & & & & & & & \\
\hline \multirow[t]{2}{*}{22} & Serotransferrin & P02787 & 6.81 & 6.14 & 18 & 23 & 188 & $2376 \pm 300^{\S}$ & $\begin{array}{r}3235 \\
\pm 879\end{array}$ & $4969 \pm 1743^{\S}$ & 0,01 & 1.36 & $2.09^{\S}$ & 1.53 & Plasma \\
\hline & & & 79280 & 79397 & & & & & & & & & & & \\
\hline \multirow[t]{2}{*}{23} & $\begin{array}{l}\text { Fibrinogen } \\
\text { gamma chain }\end{array}$ & P02679 & 5.37 & 5.52 & 10 & 28 & 133 & $511 \pm 354^{\S}$ & $766 \pm 671$ & $2649 \pm 2055^{\S}$ & 0,039 & 1.49 & $5.18^{\S}$ & 3.45 & Plasma \\
\hline & & & 52106 & 53481 & & & & & & & & & & & \\
\hline \multirow[t]{2}{*}{24} & $\begin{array}{l}\text { Alpha-1- } \\
\text { antitrypsin }\end{array}$ & P01009 & 5.37 & 5.29 & 8 & 27 & 121 & $197 \pm 222^{\S}$ & $641 \pm 651$ & $1938 \pm 1200^{\S}$ & 0,01 & 3.25 & $9.83^{\S}$ & $3.02^{*}$ & Plasma \\
\hline & & & 46878 & 54009 & & & & & & & & & & & \\
\hline
\end{tabular}

Mascot search results, mean and standard deviations, statistical $p$ values and number of folds of protein expression in the three groups. Statistical significant differences between smoking controls (sc) and nosmoking controls (nsc) are visualized by *, statistical differences between smoking controls and Pulmonary Langerhans cell Histiocytosis (PLCH) are visualized by ${ }^{*}$ and significant differences occurring between nosmoking controls and Pulmonary Langerhans cell Histiocytosis are shown by ${ }^{\$}$. The proteins quantitatively more abundant in PLCH than in non-smoker and/or smoker control samples are reported in table 3. 
Table 4 Proteins down-regulated in PLCH compared to non-smoker and/or smoker controls.

\begin{tabular}{|c|c|c|c|c|c|c|c|c|c|c|c|c|c|c|c|}
\hline \multirow{2}{*}{$\begin{array}{l}\text { No. } \\
\text { of } \\
\text { spot }\end{array}$} & \multirow[t]{2}{*}{ Protein name } & \multirow[t]{2}{*}{$A C$} & \multirow{2}{*}{$\begin{array}{l}\text { Theoretical } \\
\mathrm{pl} / \mathrm{Mr} \\
\text { (KDa) }\end{array}$} & \multirow{2}{*}{$\begin{array}{l}\text { Experimental } \\
\mathrm{pl} / \mathrm{Mr}(\mathrm{KDa})\end{array}$} & \multicolumn{3}{|c|}{ Mascot search result } & \multicolumn{3}{|c|}{ Mean $\% \mathrm{~V} \pm \mathrm{SD} \times 10^{-4}$} & \multirow{2}{*}{$\begin{array}{l}\text { 1-way } \\
\text { ANOVA } p \\
\text { value }\end{array}$} & \multicolumn{3}{|c|}{ Folds in } & \multirow[t]{2}{*}{ Localization } \\
\hline & & & & & $\begin{array}{l}\text { No. of } \\
\text { matched } \\
\text { peptide }\end{array}$ & $\begin{array}{c}\text { Sequence } \\
\text { coverage } \\
(\%)\end{array}$ & Score & nsc & sc & $\mathrm{PLCH}$ & & $\begin{array}{l}\text { Nsc- } \\
\text { sc }\end{array}$ & $\begin{array}{l}\text { Nsc- } \\
\text { PLCH }\end{array}$ & $\begin{array}{l}\text { Sc- } \\
\text { PLCH }\end{array}$ & \\
\hline \multicolumn{16}{|c|}{$\mathrm{PLCH}<\mathrm{nsc}$ and/or sc } \\
\hline \multirow[t]{2}{*}{25} & Polymeric & P01833 & 5.58 & 5.14 & 10 & 18 & 129 & $2901 \pm 438^{\S}$ & $3037 \pm 1038^{*}$ & $911 \pm 694^{¥ \S}$ & $1.31 \mathrm{E}-03$ & 1.04 & $3.18^{\S}$ & $3.33^{*}$ & Cell membrane \\
\hline & & & 84429 & 87377 & & & & & & & & & & & \\
\hline \multirow[t]{2}{*}{26} & Thioredoxin & P10599 & 4.82 & 4.67 & 6 & 40 & 82 & $665 \pm 113$ & $1492 \pm 819^{\#}$ & $230 \pm 235^{*}$ & 0,005 & 2.24 & 2.89 & $6.48^{*}$ & $\begin{array}{l}\text { Cytoplasm- } \\
\text { Secreted }\end{array}$ \\
\hline & & & 12015 & 12098 & & & & & & & & & & & \\
\hline \multirow[t]{2}{*}{27} & Plastin-2 & P13796 & 5.2 & 5.19 & 10 & 21 & 102 & $873 \pm 355$ & $1272 \pm 320^{*}$ & $453 \pm 386^{*}$ & 0,01 & 1.45 & 1.92 & $2.80^{¥}$ & $\begin{array}{l}\text { Cytoplasm- } \\
\text { Cytoskeleton-Cell } \\
\text { junktion }\end{array}$ \\
\hline & & & 70815 & 61983 & & & & & & & & & & & \\
\hline \multirow[t]{2}{*}{28} & Serum albumin & P02768 & 5.92 & 6.04 & 8 & 14 & 92 & $1830 \pm 647$ & $2980 \pm 827^{\#}$ & $1239 \pm 1363^{*}$ & 0,04 & 1.62 & 1.47 & $2.40^{*}$ & Plasma \\
\hline & & & 71317 & 57513 & & & & & & & & & & & \\
\hline \multirow[t]{2}{*}{29} & $\begin{array}{l}\text { Serum albumin, } \\
\text { fragment }\end{array}$ & P02768 & 5.92 & 6.09 & 6 & 9 & 74 & $278 \pm 137$ & $405 \pm 224^{*}$ & $124 \pm 83^{*}$ & 0,049 & 1.45 & 2.24 & $3.26^{*}$ & Plasma \\
\hline & N-term & & 71317 & 31059 & & & & & & & & & & & \\
\hline \multirow[t]{2}{*}{30} & ADP-ribosylation & P36405 & 6.74 & 7.37 & 6 & 52 & 107 & $305 \pm 161$ & $621 \pm 331^{*}$ & $142 \pm 49^{¥}$ & 0,012 & 2.03 & 2.14 & $4.37^{*}$ & Membrane \\
\hline & & & 20614 & 21404 & & & & & & & & & & & \\
\hline \multirow[t]{2}{*}{31} & $\begin{array}{l}\text { Alpha-1B- } \\
\text { glycoprotein }\end{array}$ & P04217 & 5.58 & 5.16 & 8 & 22 & 109 & $1370 \pm 414^{\S}$ & $1163 \pm 443$ & $663 \pm 83^{\S}$ & 0,022 & 1.17 & $2.06^{\S}$ & 1.75 & Plasma \\
\hline & & & 54809 & 75685 & & & & & & & & & & & \\
\hline
\end{tabular}


Table 5 Proteins differently expressed between smoker and no-smoker controls and between PLCH patients and controls.

\begin{tabular}{|c|c|c|c|c|c|c|c|c|c|c|c|c|c|c|c|}
\hline \multirow{2}{*}{$\begin{array}{l}\text { No. } \\
\text { of } \\
\text { spot }\end{array}$} & \multirow[t]{2}{*}{ Protein name } & \multirow[t]{2}{*}{$A C$} & \multirow{2}{*}{$\begin{array}{l}\text { Theoretical } \\
\mathrm{pl} / \mathrm{Mr} \\
\text { (KDa) }\end{array}$} & \multirow{2}{*}{$\begin{array}{l}\text { Experimental } \\
\mathrm{pl} / \mathrm{Mr}(\mathrm{KDa})\end{array}$} & \multicolumn{3}{|c|}{ Mascot search result } & \multicolumn{3}{|c|}{ Mean $\% \mathrm{~V} \pm \mathrm{SD} \times 10^{-4}$} & \multirow{2}{*}{$\begin{array}{c}\text { 1-way } \\
\text { ANOVA } p \\
\text { value }\end{array}$} & \multicolumn{3}{|c|}{ Folds in } & \multirow[t]{2}{*}{ Localization } \\
\hline & & & & & $\begin{array}{l}\text { No. of } \\
\text { matched } \\
\text { peptide }\end{array}$ & $\begin{array}{l}\text { Sequence } \\
\text { coverage } \\
(\%)\end{array}$ & Score & nsc & sc & $\mathrm{PLCH}$ & & $\begin{array}{l}\text { Nsc- } \\
\text { sc }\end{array}$ & $\begin{array}{l}\text { Nsc- } \\
\text { PLCH }\end{array}$ & $\begin{array}{l}\text { Sc- } \\
\text { PLCH }\end{array}$ & \\
\hline \multicolumn{16}{|c|}{$\mathrm{PLCH}<\mathrm{nsc}$ and/or sc } \\
\hline \multirow[t]{2}{*}{25} & Polymeric & P01833 & 5.58 & 5.14 & 10 & 18 & 129 & $2901 \pm 438^{\S}$ & $3037 \pm 1038^{*}$ & $911 \pm 694^{\# \S}$ & $1.31 \mathrm{E}-03$ & 1.04 & $3.18^{\S}$ & $3.33^{*}$ & Cell membrane \\
\hline & & & 84429 & 87377 & & & & & & & & & & & \\
\hline \multirow[t]{2}{*}{26} & Thioredoxin & P10599 & 4.82 & 4.67 & 6 & 40 & 82 & $665 \pm 113$ & $1492 \pm 819^{*}$ & $230 \pm 235^{*}$ & 0,005 & 2.24 & 2.89 & $6.48^{*}$ & $\begin{array}{l}\text { Cytoplasm- } \\
\text { Secreted }\end{array}$ \\
\hline & & & 12015 & 12098 & & & & & & & & & & & \\
\hline \multirow[t]{2}{*}{27} & Plastin-2 & P13796 & 5.2 & 5.19 & 10 & 21 & 102 & $873 \pm 355$ & $1272 \pm 320^{*}$ & $453 \pm 386^{*}$ & 0,01 & 1.45 & 1.92 & $2.80^{*}$ & $\begin{array}{c}\text { Cytoplasm- } \\
\text { Cytoskeleton-Cell } \\
\text { junktion }\end{array}$ \\
\hline & & & 70815 & 61983 & & & & & & & & & & & \\
\hline \multirow[t]{2}{*}{28} & Serum albumin & P02768 & 5.92 & 6.04 & 8 & 14 & 92 & $1830 \pm 647$ & $2980 \pm 827^{\#}$ & $1239 \pm 1363^{*}$ & 0,04 & 1.62 & 1.47 & $2.40^{*}$ & Plasma \\
\hline & & & 71317 & 57513 & & & & & & & & & & & \\
\hline \multirow[t]{2}{*}{29} & $\begin{array}{l}\text { Serum albumin, } \\
\text { fragment }\end{array}$ & P02768 & 5.92 & 6.09 & 6 & 9 & 74 & $278 \pm 137$ & $405 \pm 224^{*}$ & $124 \pm 83^{*}$ & 0,049 & 1.45 & 2.24 & $3.26^{*}$ & Plasma \\
\hline & N-term & & 71317 & 31059 & & & & & & & & & & & \\
\hline \multirow[t]{2}{*}{30} & ADP-ribosylation & P36405 & 6.74 & 7.37 & 6 & 52 & 107 & $305 \pm 161$ & $621 \pm 331^{*}$ & $142 \pm 49^{*}$ & 0,012 & 2.03 & 2.14 & $4.37^{*}$ & Membrane \\
\hline & & & 20614 & 21404 & & & & & & & & & & & \\
\hline \multirow[t]{2}{*}{31} & $\begin{array}{l}\text { Alpha-1B- } \\
\text { glycoprotein }\end{array}$ & P04217 & 5.58 & 5.16 & 8 & 22 & 109 & $1370 \pm 414^{\S}$ & $1163 \pm 443$ & $663 \pm 83^{8}$ & 0,022 & 1.17 & $2.06^{\S}$ & 1.75 & Plasma \\
\hline & & & 54809 & 75685 & & & & & & & & & & & \\
\hline
\end{tabular}

This table is divided in two parts: the first part includes protein spots significantly down-regulated in non-smoker compared to smoker controls; the second part includes spots up-regulated in non-smoker than smoker controls. 


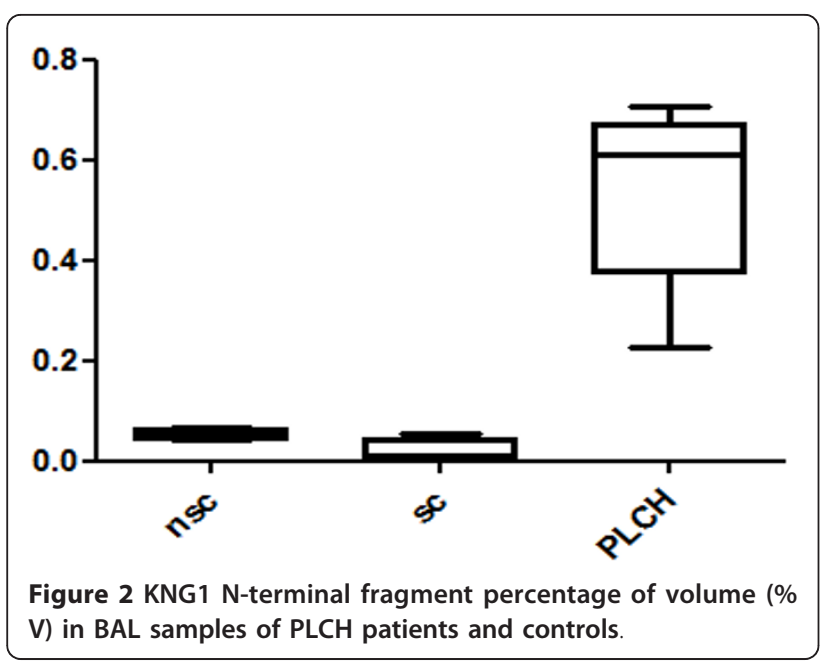

of protease inhibitors involved in cell survival and associated with lung cancer [24]. The second protein, plastin 2 , member of a large family of actin filament cross-linkers, was down-regulated in PLCH patients with respect to smoker controls. Plastin 2 triggers immune response, cell migration, proliferation and cell-adhesion [25] and its role in actin cytoskeleton rearrangement and T-cell activation is crucial. Another function of plastin 2 is protection against TNF-cytotoxicity [26]. As cigarette smoke may induce production of tumor necrosis factoralpha (TNF- $\alpha$ ) by alveolar macrophages [27], up-regulation of PLSL2 in BAL of smokers may have a protective role against this pro-inflammatory cytokine. Interestingly in our PLCH patients this mechanism was downregulated.

The results of our proteome analysis of PLCH BAL suggested the involvement of some immunoinflammatory

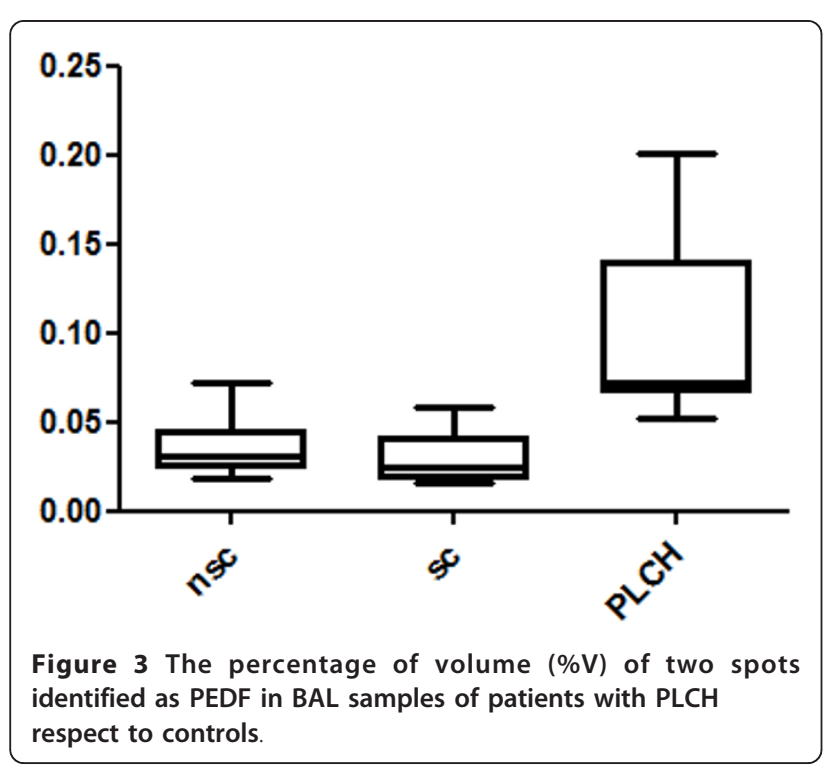

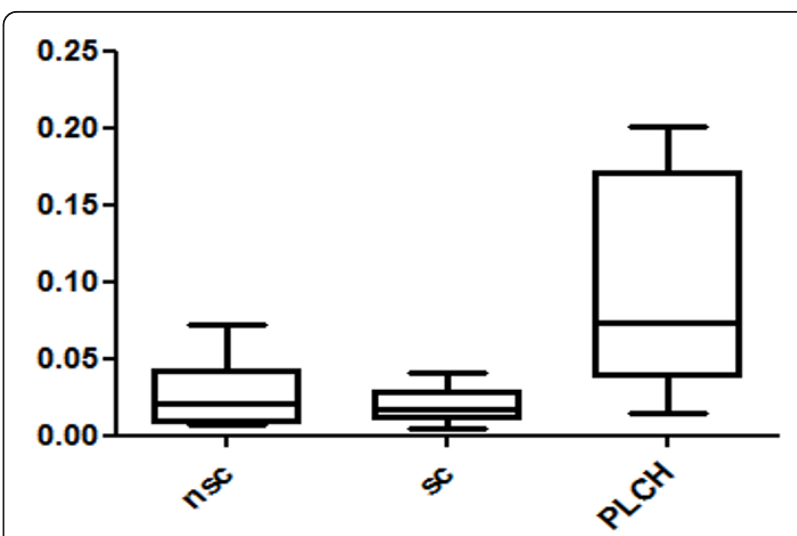

Figure 4 Annexin A3 (ANXA3) \%V in BAL of PLCH patients smoker controls and no-smoker controls.

pathways in its pathogenesis, which remains obscure. For example, the profibrotic effect of certain proteins could play a key role in development of PLCH. Pigment epithelium derived factor (PEDF) is a protein known to be involved in fibrogenesis. In our study PEDF was significantly higher in BAL samples of PLCH patients than smoker and no-smoker controls. This protein is an endogenous anti-angiogenic factor [28] implicated in a variety of diseases in which angiogenesis is critical, such as nonsmall cell lung cancer and IPF [28-31]. Immunohistochemical studies on IPF located PEDF in fibroblastic foci and areas of active matrix synthesis, where vascular density is low [31]. Recent research indicates that PEDF can be regarded as a TGF $\beta 1$-mediated profibrotic agent [32]. These findings suggest that PEDF may be implicated in the regulation of vascular and fibrotic damage occurring in PLCH.

The role of angiogenesis in the pathophysiology of $\mathrm{PLCH}$ is controversial. Little data is available about neovascularization in PLCH [33]. Senechal et al. recently

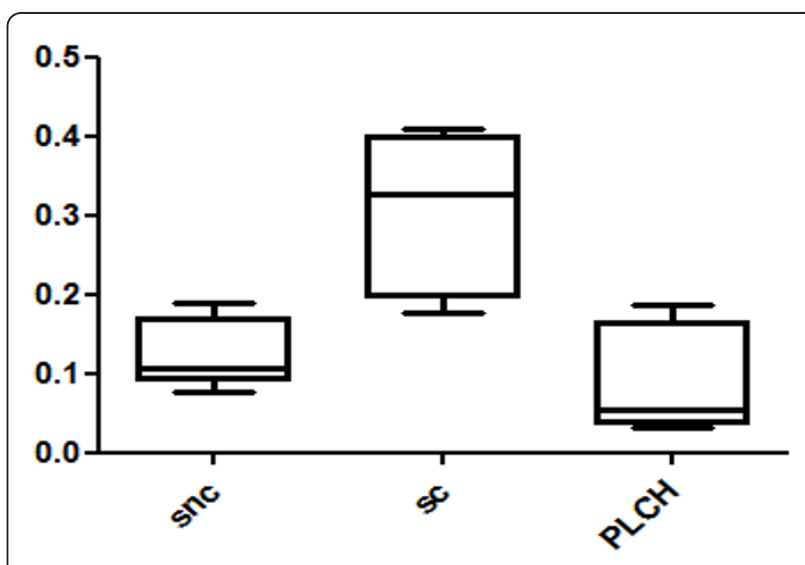

Figure 5 Polymeric Immunoglobulin Receptor (PIGR) \%V in BAL of PLCH patients smoker controls and no-smoker controls. 


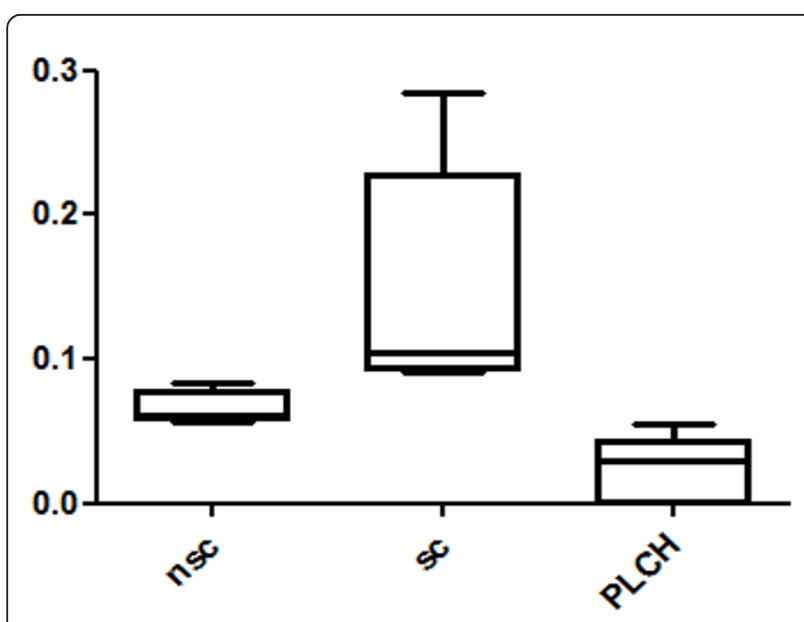

Figure 6 Thioredoxin (THIO) in BAL samples of PLCH patients compared with smoker controls and no-smoker controls.

reported that PLCH lesions were sites of neoangiogenesis and tissue remodelling [34], whereas an immunohistochemical analysis by Zielonka et al. indicated that PLCH granulomas are connected with areas of extensive neoangiogenesis in which interleukin 1 alpha (IL-1 $\alpha$ ) and TNF- $\alpha$ are over-expressed [35]. In contrast to these lung tissue results, it has also been found that serum from PLCH patients inhibited angiogenesis [35]. Our study demonstrated that several proteins implicated in vascular remodelling were up-regulated in BAL of $\mathrm{PLCH}$ patients versus controls. Annexin A3, for example, is a calcium- and phospholipid-binding protein involved in angiogenesis as well as in cell proliferation, motility, invasiveness and signaling pathways [36,37]. This protein, up-regulated in $\mathrm{PLCH}$ patients with respect to controls, is reported in the literature to be over-expressed in lung adenocarcinoma associated with metastases [38]. Its multiple functions in PLCH pathogenesis warrants further investigation.

Our study suggests an imbalance between protease and anti-protease with consequent proteolytic-mediated lung damage potentially involved in the pathogenesis of $\mathrm{PLCH}$, confirming previous observations [39]. In fact, we found a great abundance of proteolytic fragments of plasma proteins in BAL of PLCH patients, suggesting increased proteolytic activity. In particular kininogen 1 and haptoglobin proteolytic fragments were more highly expressed in BAL of PLCH patients than BAL of controls. An increased anti-proteolytic activity was found expressed by the significant increase of five isoforms of alpha 1-antitrypsin in BAL of PLCH patients with respect to smoker and/or non-smoker controls [39].

Several studies have analyzed smoke-induced oxidative stress in normal subjects but little data is available on the potential role of oxidation in PLCH [40].
Glutathione peroxidase 3 is an antioxidant protein with a protective role against cigarette smoke-induced lung inflammation [41]. It protects cells and enzymes against oxidative damage by catalyzing the reduction of hydrogen peroxide, lipid peroxides and organic hydroperoxide by glutathione [41]. Interestingly, in our research this protein was significantly higher in smoker than nonsmoker controls but almost absent in BAL of PLCH patients (who were all smokers). It should be investigated if there is a defective production or/and an increased consumption in PLCH, as it has been demonstrated that oxidative stress is generally higher in PLCH patients than smoker controls [40]. Thioredoxin was another antioxidant protein down-regulated in BAL of $\mathrm{PLCH}$ patients with respect to smoker controls. It plays a protective role against cigarette smoke-induced lung oxidative damage $[42,43]$ and reacts against reactive oxygen species (ROS) and other free radicals which are considered causative factors of smoke-related diseases in humans [44]. Thioredoxin counteracts Th2-driven airway inflammation by suppressing local production of macrophage migration inhibitory factor (MIF), irrespective of systemic Th1/Th2 immune modulation [45]. Interestingly, THIO is not only down-regulated in PLCH but also in idiopathic pulmonary fibrosis (IPF) [46].

Polymeric immunoglobulin receptor is a transmembrane protein involved in mucosal immunity (mediating transcytosis of polymeric IgA and $\operatorname{IgM}$ ) $[47,48]$. This protein was significantly down-regulated in BAL of $\mathrm{PLCH}$ patients with respect to controls. Stress, smoking and inflammation can modulate PIGR production through TNF- $\alpha$ and interleukin-1 $\beta$ (IL1 $\beta$ ), allowing translation of systemic inflammatory signals into mucosal immune responses [49], this mechanism seems to be compromised in PLCH. Recruitment of Langerhans cells in the lungs during exposure to smoke may induce $\mathrm{T}$ helper 1 and T-helper 17 responses in CD4 T cells. Th17 cells produce interleukin 17 (IL17) that enhances secretion of CCL20, a chemoattractant for dendritic cells and matrix metalloproteinase 12 from lung macrophages [50,51]. Th17 and Th1 also promote PIGR activity by production of IL-17 and IL-1 [47]; this mechanism creates feedback that induces inflammatory cell recruitment and lung destruction [47]. The large quantity of Th17 in smoke-exposed lungs may therefore explain the high levels of PIGR required to amplify the mucosal immune response in BAL of smokers. This protein showed a different pattern in PLCH than in healthy smokers being decreased in PLCH, although PLCH patients were all smokers, suggesting a possible pathogenetic (not smoking related) role. PIGR, Th1 and Th17 immune responses should be deeply investigated in PLCH. 


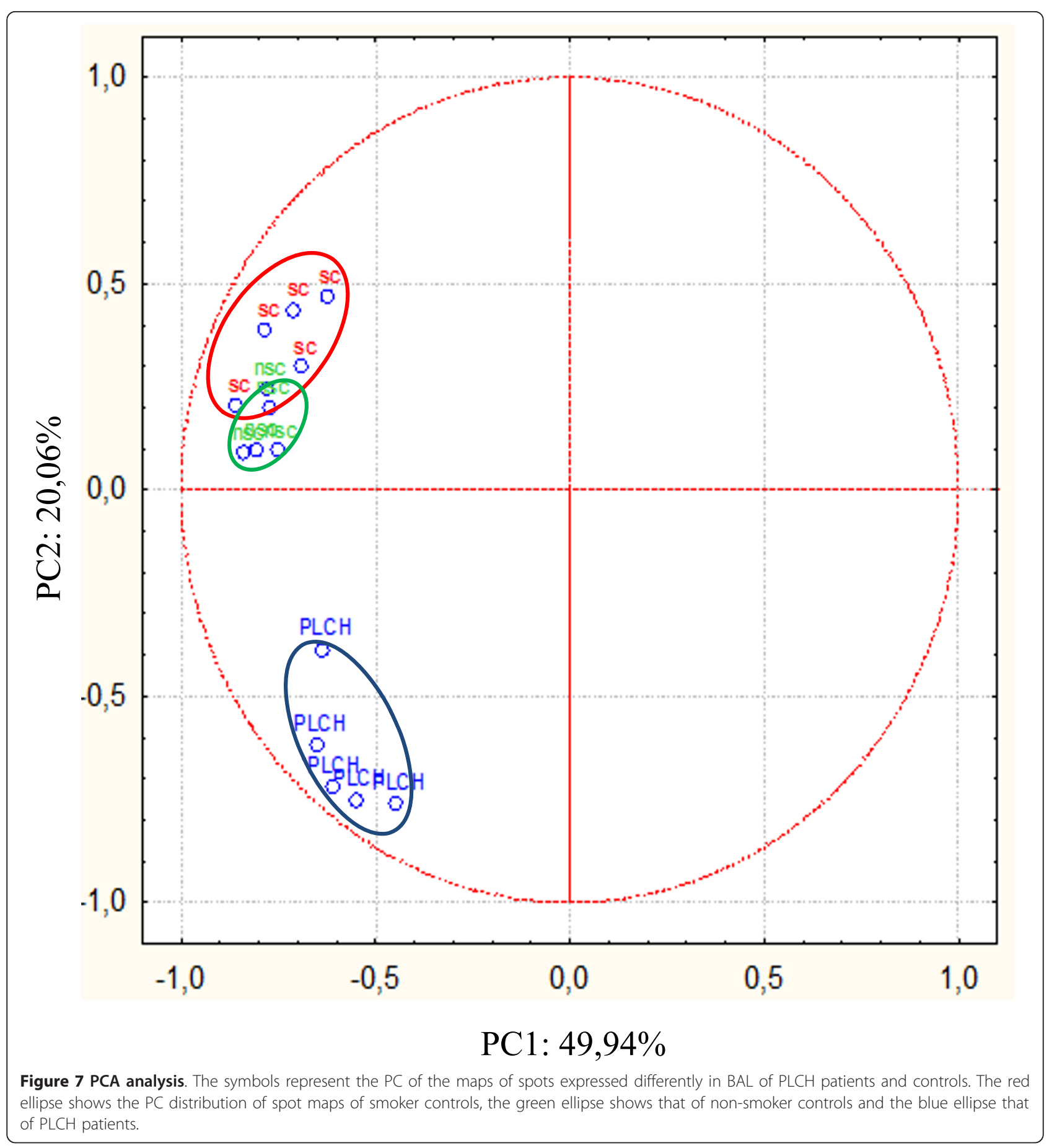

Another interesting protein potentially involved in PLCH pathogenesis could be annexin A1, a cell mediator of the anti-inflammatory action of glucocorticoid [52] that inhibits neutrophil extravasation [53]. The inflammatory environment induced by smoking is associated with increased epithelial permeability to neutrophils, macrophages and myeloid dendritic cells $[4,42,54]$. Complete loss of ANXA1 found in BAL of PLCH patients may lead to reduced response to steroids, overrecruitment of neutrophils in the lungs and loss of negative feedback for extravasation.

\section{PCA}

In this study, PCA and analysis of the patterns of proteins differently expressed enabled us to distinguish our BAL samples into three groups (PLCH patients and 
smoker and non-smoker controls), which was one of our aims. Very high reproducibility was observed between BAL samples and distinct expression patterns in the three groups. Conducting multivariate analysis by PCA, we distinguished three groups in relation to the PC2 $y$ axis, and observed that non-smoker and smoker controls were both in the upper part of the graph, close together. This suggested that their patterns of protein expression were more similar to each other than to the PLCH group, despite the fact that they, too, were clearly separated, not only suggesting similar characteristics but also that exposure to cigarette smoke induced a modest change in the pattern of protein expression in BAL (smokers versus non-smokers). The position of the PLCH group on the opposite side of PC2 with respect to controls confirmed that the disease group had a protein profile different from that found in a condition of health (Figure 7).

In conclusion, proteomic analysis of BAL from patients with PLCH and smoker and non-smoker controls distinguished proteins up- and down-regulated in the disease differently expressed from smoker controls and than disease-related. Among these proteins there were PIGR and thioredoxin. The observation that certain proteins, over-expressed in PLCH patients, are also elevated in IPF suggests common pathways for the development of lung fibrosis [55]. Our proteomic study also indicates that oxidative stress, proteolysis and angiogenetic factors may be involved in the pathogenesis of PLCH, although further studies are needed also to assess the impact of other agents including pollution. Our future aim will be to further investigate the functions of the proteins of interest, their potential modifications induced by local damage (i.e. oxidation and proteolysis) and to validate the present results on a larger patients population.

\section{Abbreviations}

PLCH: pulmonary Langerhans cell histiocytosis; BAL: bronchoalveolar lavage; HRCT: high resolution computed tomography; PFT: pulmonary function test; 2DE: two-dimensional electrophoresis; MS: mass spectrometry.

\section{Author details}

'Respiratory Diseases Section, Department of Clinical Medicine and Immunological Sciences, University of Siena, Siena (Italy. ${ }^{2}$ Department of Biotechnologies, University of Siena, Siena (Italy. ${ }^{3}$ Department of Pneumology, Ludwig University, Freiburg (Germany.

\section{Authors' contributions}

EB corresponding author, design study, CL analysis and acquisition of data, PR study coordination, elaboration of results, LB critical revision, analysis of results, BM elaboration of results, critical revision, AP analysis, design study, JMQ conception and design of the study. All authors read and approved the final manuscript.

\section{Competing interests}

The authors declare that they have no competing interests.
Received: 6 August 2011 Accepted: 10 November 2011

Published: 10 November 2011

\section{References}

1. Torre O, Harari S: The diagnosis of cystic lung diseases: a role for bronchoalveolar lavage and transbronchial biospy? Respiratory Medicine 2010, 104:S81e-S85.

2. Sundar KM, Gosselin MV, Chung HL, Cahill BC: Pulmonary Langerhans Cell Histiocytosis: Emerging Concepts in Pathobiology, Radiology, and Clinical Evolution of Disease. Chest 2003, 123:1673-1683.

3. Rao RN, Goodman LR, Tomashefski JF Jr: Smoking-related interstitial lung disease. Ann Diagn Pathol 2008, 12(6):445-57.

4. Lommatzsch M, Bratke K, Knappe T, Bier A, Dreschler K, Kuepper M, Stoll P, Julius $P$, Virchow JC: Acute effects of tobacco smoke on human airway dendritic cells in vivo. Eur Respir J 2010, 35(5):1130-6.

5. Bratke K, Klug M, Bier A, Julius P, Kuepper M, Virchow JC, Lommatzsch M: Function-associated surface molecules on airway dendritic cells in cigarette smokers. Am J Respir Cell Mol Biol 2008, 38(6):655-60.

6. Soler P, Moreau A, Basset F, Hance AJ: Cigarette smoking-induced changes in the number and differentiated state of pulmonary dendritic cells/Langerhans cells. Am Rev Respir Dis 1989, 139(5):1112-7.

7. Vassallo R, Walters PR, Lamont J, Kottom TJ, Yi ES, Limper AH: Cigarette smoke promotes dendritic cell accumulation in COPD; a lung tissue research consortium study. Respir Res 2010, 11-45.

8. Magi B, Bargagli E, Bini L, Rottoli P: Proteome analysis of BAL in lung diseases. Proteomics 2006, 6(23):6354-69.

9. Aricò M: Langerhans cell histiocytosis in adults: more questions than answers? Eur J Cancer 2004, 40:1467-1473.

10. Crausman RS: Pulmonary histiocytosis $\mathrm{X}$ : pulmonary function and exercise pathophysiology. Am J Respir Crit Care Med 1996, 153:426-35.

11. Vassallo R: Pulmonary Langerhans cell histiocytosis. N Engl J Med 2000, 342:1969-1978.

12. ATS/ERS: Standardisation of lung function testing. Eur Respir J 2005, 26:319-38.

13. Bargagli E, Bigliazzi C, Leonini A, et al: Tryptase concentrations in bronchoalveolar lavage from patients with chronic eosinophilic pneumonia. Clin Sci (London) 2005, 108(3):273-276.

14. Bargagli E, Margollicci MA, Luddi A, et al: Chitotriosidase activity in patients with diffuse lung diseases. Respir Med 2007, 101(10):2176-81.

15. Bargagli E, Margollicci M, Perrone A, et al: Chitotriosidase analysis in BAL of patients with sarcoidosis. Sarcoidosis Vasc Diffuse Lung Dis 2007, 24(1):59-64.

16. Bradford MM: A rapid and sensitive method for the quantitation of microgram quantities of protein utilizing the principle of protein-dye binding. Anal Biochem 1976, 72:248-254.

17. Bjellqvist B, Pasquali C, Ravier F, Sanchez JC, Hochstrasser D: A nonlinear wide-range immobilized $\mathrm{pH}$ gradient for two-dimensional electrophoresis and its definition in a relevant $\mathrm{pH}$ scale. Electrophoresis 1993, 14:1357-1365.

18. Hochstrasser DF, Harrington MG, Hochstrasser AC, Miller MJ, Merril CR: Methods for increasing the resolution of two-dimensional protein electrophoresis. Anal Biochem Sep 1988, 173(2):424-35.

19. Oakley BR, Kirsch DR, Morris NR: A simplified ultrasensitive silver stain for detecting proteins in polyacrylamide gels. Anal Biochem 1980, 105:361-363.

20. Hochstrasser DF, Patchornik A, Merril CR: Development of polyacrylamide gels that improve the separation of proteins and their detection by silver staining. Anal Biochem 1988, 173:412-423.

21. Cañas B, Piñeiro C, Calvo E, López-Ferrer D, Gallardo JM: Trends in sample preparation for classical and second generation proteomics. J Chromatogr A 2007, 1153(1-2):235-58.

22. Hellman U, Wernstedt C, Gonez J, Heldin CH: Improvement of an "In-Gel" digestion procedure for the micropreparation of internal protein fragments for amino acid sequencing. Anal Biochem 1995, 224:451-455.

23. Soskic V, Gorlach M, Poznanovic S, Boehmer FD, Godovac-Zimmermann J: Functional proteomics analysis of signal transduction pathways of the platelet-derived growth factor beta receptor. Biochemistry 1999, 38:1757-1764.

24. Ahmed ST, Darnell JE: Serpin B3/B4, activated by STAT3, promote survival of squamous carcinoma cells. Biochem Biophys Res Commun 2009, 378:821-5. 
25. Janji B, Giganti A, De Corte V, Catillon M, Bruyneel E, Lentz D, Plastino J, Gettemans J, Friederich E: Phosphorylation on Ser5 increases the F-actinbinding activity of L-plastin and promotes its targeting to sites of actin assembly in cells. J Cell Sci 2006, 119(Pt 9):1947-60.

26. Janji B, Vallar L, Al Tanoury Z, Bernardin F, Vetter G, Schaffner-Reckinger E, Berchem G, Friederich E, Chouaib S: The actin filament cross-linker Lplastin confers resistance to TNF-alpha in MCF-7 breast cancer cells in a phosphorylation-dependent manner. J Cell Mol Med 2010, 14(6A):1264-75.

27. Petrescu F, Voican SC, Silosi I: Tumor necrosis factor-alpha serum levels in healthy smokers and nonsmokers. Int J Chron Obstruct Pulmon Dis 2010, 5:217-22.

28. Chen J, Ye L, Zhang L, Jiang WG: The molecular impact of pigment epithelium-derived factor, PEDF, on lung cancer cells and the clinical significance. Int J Oncol 2009, 35(1):159-66.

29. Rodríguez-Piñeiro AM, Blanco-Prieto S, Sánchez-Otero N, RodríguezBerrocal FJ, de la Cadena MP: On the identification of biomarkers for non-small cell lung cancer in serum and pleural effusion. J Proteomics 2010, 73(8):1511-22.

30. Broadhead ML, Dass CR, Choong PF: Cancer cell apoptotic pathways mediated by PEDF: prospects for therapy. Trends Mol Med 2009, 15(10):461-7.

31. Cosgrove GP, Brown KK, Schiemann WP, Serls AE, Parr JE, Geraci MW, Schwarz MI, Cool CD, Worthen GS: Pigment epithelium-derived factor in idiopathic pulmonary fibrosis: a role in aberrant angiogenesis. Am J Respir Crit Care Med 2004, 170(3):242-51.

32. Szlubowski A, Soja J, Grzanka P, Tomaszewska R, Papla B, Kuzdzał J, Cmiel A Sładek K: TGF-beta1 in bronchoalveolar lavage fluid in diffuse parenchymal lung diseases and high-resolution computed tomography score. Pol Arch Med Wewn 2010, 120(7-8):270-5.

33. Zielonka TM, Demkow U, Puscinska E, Golian-Geremek A, Filewska M, Zycinska K, Białas-Chromiec B, Wardyn KA, Skopińska-Rózewska E: TNFalpha and INFgamma inducing capacity of sera from patients with interstitial lung disease in relation to its angiogenesis activity. J Physiol Pharmacol 2007, 58(Suppl 5 Pt 2):767-80.

34. Senechal B, Elain G, Jeziorski E, Grondin V, Patey-Mariaud de Serre N, Jaubert F, Beldjord K, Lellouch A, Glorion C, Zerah M, Mary P, Barkaoui M, Emile JF, Boccon-Gibod L, Josset P, Debré M, Fischer A, Donadieu J, Geissmann F: Expansion of regulatory $T$ cells in patients with Langerhans cell histiocytosis. PLoS Med 2007, 4(8):e253.

35. Zielonka TM, Demkow U, Filewska M, Bialas-Chromiec B, Zycinska K, Radzikowska E, Korzeniewska M, Wardyn KA, Kus J, Skopinska-Rozewska E: Angiogenic activity of sera from silicosis and pulmonary Langerhans cell histiocytosis patients in relation to lung function tests. J Physiol Pharmacol 2008, 59(Suppl 6):781-9.

36. Rescher $U$, Gerke V: Annexins-unique membrane binding proteins with diverse functions. J Cell Sci 2004, 117(Pt 13):2631-9.

37. Park JE, Lee DH, Lee JA, Park SG, Kim NS, Park BC, Cho S: Annexin A3 is a potential angiogenic mediator. Biochem Biophys Res Commun 2005, 337(4):1283-7.

38. Liu YF, Xiao ZQ, Li MX, Li MY, Zhang PF, Li C, Li F, Chen YH, Yi H, Yao HX, Chen $Z C$ : Quantitative proteome analysis reveals annexin $A 3$ as a novel biomarker in lung adenocarcinoma. J Pathol 2009, 217(1):54-64.

39. Wood AM, Stockley RA: Alpha one antitrypsin deficiency: from gene to treatment. Respiration 2007, 74(5):481-92.

40. Brown RE: Oxidative stress, p53expression, and cytogenetic abnormalities in Langerhans cell histiocytosis. Med Pediatr Oncol 2002, 38(1):70-1.

41. Duong C, Seow HJ, Bozinovski S, Crack PJ, Anderson GP, Vlahos R: Glutathione peroxidase-1 protects against cigarette smoke-induced lung inflammation in mice. Am J Physiol Lung Cell Mol Physiol 2010, 299(3): L425-33.

42. Morrison D, Rahman I, Lannan S, MacNee W: Epithelial permeability, inflammation, and oxidant stress in the air spaces of smokers. Am J Respir Crit Care Med 1999, 159(2):473-9.

43. Huang YL, Chuang CY, Sung FC, Chen CY: Thioredoxin overexpression modulates remodeling factors in stress responses to cigarette smoke. $J$ Toxicol Environ Health A 2008, 71(22):1490-8.

44. Zhang S, Xu N, Nie J, Dong L, Li J, Tong J: Proteomic alteration in lung tissue of rats exposed to cigarette smoke. Toxicol Lett 2008, 178(3):191-6.

45. Torii M, Wang L, Ma N, Saito K, Hori T, Sato-Ueshima M, Koyama Y, Nishikawa H, Katayama N, Mizoguchi A, Shiku H, Yodoi J, Kuribayashi K,
Kato T: Thioredoxin suppresses airway inflammation independently of systemic Th1/Th2 immune modulation. Eur J Immunol 2010, 40(3):787-96.

46. Rottoli P, Magi B, Perari MG, Liberatori S, Nikiforakis N, Bargagli E, Cianti R, Bini $L$, Pallini V: Cytokine profile and proteome analysis in bronchoalveolar lavage of patients with sarcoidosis, pulmonary fibrosis associated with systemic sclerosis and idiopathic pulmonary fibrosis. Proteomics 2005, 5(5):1423-30.

47. Jaffar Z, Ferrini ME, Herritt LA, Roberts K, Cutting edge: lung mucosal Th17mediated responses induce polymeric Ig receptor expression by the airway epithelium and elevate secretory IgA levels. J Immunol 2009, 182(8):4507-11.

48. Kaetzel CS: The polymeric immunoglobulin receptor: bridging innate and adaptive immune responses at mucosal surfaces. Immunol Rev 2005, 206:83-99.

49. Sano Y, Hermsen JL, Kang W, Gomez FE, Lan J, Maeshima Y, Kudsk KA Parenteral nutrition maintains pulmonary IgA antibody transport capacity, but not active transport, following injury. Am J Surg 2009, 198(1):105-9.

50. Shan M, Cheng HF, Song LZ, Roberts L, Green L, Hacken-Bitar J, Huh J, Bakaeen F, Coxson HO, Storness-Bliss C, Ramchandani M, Lee SH, Corry DB, Kheradmand F: Lung myeloid dendritic cells coordinately induce TH1 and TH17 responses in human emphysema. Sci Transl Med 2009, 1(4):4ra10.

51. Harrison OJ, Foley J, Bolognese BJ, Long E, Podolin PL, Walsh PT: Airway infiltration of CD4+ CCR6+ Th17 type cells associated with chronic cigarette smoke induced airspace enlargement. Immunol Lett 2008, 121(1):13-21.

52. Yang YH, Morand EF, Getting SJ, Paul-Clark M, Liu DL, Yona S, Hannon R, Buckingham JC, Perretti M, Flower RJ: Modulation of inflammation and response to dexamethasone by Annexin 1 in antigen-induced arthritis. Arthritis Rheum 2004, 50(3):976-84.

53. Perretti M, Gavins FN: Annexin 1: an endogenous anti-inflammatory protein. News Physiol Sci 2003, 18:60-4.

54. Woodruff PG, Koth LL, Yang YH, Rodriguez MW, Favoreto S, Dolganov GM, Paquet AC, Erle DJ: A distinctive alveolar macrophage activation state induced by cigarette smoking. Am J Respir Crit Care Med 2005, 172(11):1383-92.

55. Cianti R, Bargagli $E$, Landi $C$, et al: Proteomic analysis of BAL in patients with PLCH. Proceedings Conference Siena From Genome to Proteome 2008, s163.

doi:10.1186/2043-9113-1-31

Cite this article as: Landi et al:: Proteome analysis of bronchoalveolar lavage in pulmonary langerhans cell histiocytosis. Journal of Clinical Bioinformatics 2011 1:31.

\section{Submit your next manuscript to BioMed Central and take full advantage of:}

- Convenient online submission

- Thorough peer review

- No space constraints or color figure charges

- Immediate publication on acceptance

- Inclusion in PubMed, CAS, Scopus and Google Scholar

- Research which is freely available for redistribution

Submit your manuscript at www.biomedcentral.com/submit
C Biomed Central 